\title{
The Impact of North Shaanxi Paper Cutting on Local Regional Visual Design
}

\author{
Chunhua Jia \\ Art Institute, Yulin University, Yulin, Shaanxi, China \\ 317950860@qq.com
}

\begin{abstract}
Keywords: Folk paper-cut in Northern Shaanxi; Regional culture; Regional visual design; Nationalization
\end{abstract}

\begin{abstract}
Folk paper-cut in Northern Shaanxi is an important part of folk art of paper cutting on the Loess Plateau. The cultural and ideological connotation of regional domain. Starting from the artistic form, characteristics, modeling and connotation of paper cutting in Northern Shaanxi, this paper tries to find out the cultural connotations in the design and development of Northern Shaanxi from the perspective of economic development in Northern Shaanxi. In order to find out the enlightenment to the regional design of the Northern Shaanxi paper-cut art, we find out the simple modeling language, composition way, rich subject matter, image culture and creative thinking, and find the process of combining the Northern Shaanxi design with the local folk culture, and hope to take the paper cutting to the north of Shaanxi. The impact of regional design as an example provides a reference for the development of regional visual design in China.
\end{abstract}

\section{Introduction}

The folk paper-cut art in Northern Shaanxi has become a wonderful work of folk art in China. The design of the folk art and folk culture will inevitably become an important representative of the national culture. The unique style and folk inheritance of folk paper-cut in Northern Shaanxi has been implanted into the people's life, so that the design of the subject can be recognized and praised by the masses. At present, in the relevant research at home and abroad, it mainly includes the exploration of the folk paper-cut art, the relationship between the modeling language of paper cutting and the contemporary design, the generality of the paper cutting art and the modern design, and the application of the paper cutting art in the design. [1,2,3]

This article mainly explores the influence of local folk art on the local visual design, and limits the region to the unique region of Northern Shaanxi, which limits the content of folk art to the form of paper cutting, providing more design elements for the development of regional design. [4,5]The folk paper-cut in Northern Shaanxi is compared to a "mirror". It is not only the product of the national character, the spirit of the times, the social thought and so on, but more importantly, it is the reflection of the traditional Chinese thought and soul in the modern design, and it is used in the design to reflect the national character, the spirit of the times and the social thought of the people of Northern Shaanxi. [6,7]

\section{The Status of Regional Visual Design in Northern Shaanxi}

Northern Shaanxi is part of the Northwest Plateau, and the North Shaanxi is a typical underdeveloped area. The underdeveloped areas are described here as relatively developed areas. Taking the southeast coastal areas of our country as an example, the policy of regional tilt for the development strategy in the early stage of reform and opening to the outside world, our government according to Deng Xiaoping "let a part of the people get rich first." The strategic thinking has made 
major adjustments to the regional development strategy. [8, 9,10]Using many preferential policies of the state, these regions have actively created the economic environment, grabbed the development opportunities given by history, took the lead in entering the market, widened the space for the allocation of resources, formed a multi-channel enrichment, and initially completed the accumulation of primitive capital, so that the regional advantages, industrial competitive advantages and human resources advantages of these areas were all obtained. The full play and the large-scale inflow of foreign capital have greatly relieved the constraints of the scarcity factor - the shortage of capital supply, and brought advanced technology and management experience, laid a solid material foundation for further development, and more importantly, its institutional environment and economic environment have been unprecedentedly promoted. In recent years, the economic development is rapid. The characteristics of regional economic construction are quite distinct, mainly manifested in three aspects: natural resources, social culture and ecological environment.

The rapid development of economy in Northern Shaanxi is both a challenge and an opportunity for the regional design of Northern Shaanxi. Along with the rapid economic development, Yanan and Yulin, the two largest cities in Northern Shaanxi, have also witnessed some problems in their economic development. The challenge is that the rapid development of the economy has led to the loss of the design of the culture based design, that is, the economic construction and design is out of line. The main feature of the design is the foresight. If the design is developed, the rapid development of the economy and the cultural construction will lose contact, the development of the lack of Ideological and cultural foundation. The opportunity is the emergence of the economy, which makes people begin to attach importance to the design and construction, and better develop regional design to serve the development of the economy. In this way, we need to discover the local cultural, cultural and cultural forms in Northern Shaanxi. At present, the regional design of Northern Shaanxi is not mature, and some enterprises and organizations are seeking to integrate the design content with the international design, but ignore the deep cultural background of the local folk culture.

\section{The Relationship Between Paper-cut and Visual Design}

Paper cutting, as a folk culture, has its own attributes. In the reaction of ideological content, two aspects should be reflected in the form of reflecting the real life and the ideal of the ideal of life. There are both objective and realistic imitation, and a new style of processing and creation. Compared with traditional folk paper-cut, design is a new cultural activity, but its origin is relatively early. Paper-cut as folk art activity was first shown as decoration. In ancient times, paper-cut was the first manifestation of the formation of design patterns, using hollow paper cuts to serve other artistic creation categories, serving the needs of various aspects of life.

This can be found in the common point of paper cutting and design. First, people in life, the product created, all have the idea and implementation behavior, secondly, there are decorative painting language, expression of the same place, and again, graphical language of the description, with the characteristics of image, symbolization and graphics, finally cut. Both the paper and the design are in pursuit of image. Their form of expression demands simplicity, generosity, rhythm and rhythm.

\section{The Performance of Northern Shaanxi Paper-Cut Art in Local Regional Visual Design}

The folk paper-cut in Northern Shaanxi is very important in the status of folk paper-cut in our country. There are countless connections between the paper cutting and the design, with the style 
and content of the local paper-cut mainly, providing more folk culture content and expression form for the development of local regional design.

In the survey of regional visual design in Northern Shaanxi, it is found that local regional design is not reduced from commodity design to large environmental design, and the response of local culture is not clear enough. It is difficult to convey the revelation of the regional culture of the Northern Shaanxi to the local people's life. The simple, enthusiastic, positive and healthy aesthetic taste can not be fully realized. Sure.

\section{The Influence of North Shaanxi Paper Cutting on Local Regional Visual Design}

Northern Shaanxi culture is a special cultural area with Chinese nationality. The folk paper-cut culture is filled with the profound culture and humanistic feelings of the people in Northern Shaanxi. In the process of local regional economic development, the design of Northern Shaanxi is also advancing step by step to make bridgehead for economic development. Now, the development of regional design in Northern Shaanxi has gradually emerged, not only to study the excellent design at home and abroad, but also to excavate the excellent local cultural resources. The position of folk art in Northern Shaanxi has been increasing, and the factory in the field of culture and art in and outside the country is widely praised.

The characteristics of paper cutting in Northern Shaanxi are the most clear, and the combination of the design is more closely. Some local buildings, special products packaging, decoration and tourism resources design are also in search of the common features of folk paper-cut in Northern Shaanxi, adding new elements to the content of the design. Such as the series package of four sister son agricultural products hair Co., Ltd. in Northern Shaanxi Province, the product packaging adopts the symbol of the abstract cave graphics and Chinese characters in the product packaging. In the middle, the flower cloth runs through the folk cloth of Northern Shaanxi and the folk cloth of the Northern Shaanxi Province is anastomosed. The packaging and paper cutting style farmers feed the lambs to feed the grass, which highlights the regional culture of Northern Shaanxi. The combination of folk paper-cut and local design is a successful example.

As the root of regional design, it must be based on the national culture. The folk paper-cut in Northern Shaanxi contains rich historical culture and ancient Chinese philosophy. The important role of the development of folk paper cutting in regional design is not only to inherit folk traditional paper-cut patterns, but also to lay a deep cultural foundation for the development of the regional design.

\section{Conclusion}

The accelerated development of globalization has been developing rapidly both in terms of ideology and technology. Although the consistency and uniformity of global design are very convenient for the development of global information, there are still stereotyped shortcomings. Globalization design is assimilating the national, national and traditional designs. How to maintain the cultural and design features of the country and the region, and how to coordinate the international and national, global and local characteristics, economic centers and cultural traditions are becoming more and more concerned by the designers, and also the problems to be discussed and solved.

\section{References}

[1] Symbol of clothing color [J]. Anne snow. Youth years. 2012 (02) (in Chinese) 
[2] On the interaction and application of folk paper-cut and costume design in Shaanxi [J]. Zhang Yufan. Contemporary art. 2011 (01) (in Chinese)

[3] Analysis of the differences in the style of the paper cutting area in Northern Shaanxi [J]. Wang Jie. Today's South China (mid October). 2010 (07) (in Chinese)

[4] Research on the development trend of casual wear [J]. Han Yao Hong. Technology wind. 2009 (23) (in Chinese)

[5] On traditional costume color ethics [J]. Yang Fengfei modern communication. 2009 (06) (in Chinese)

[6] Application of folk paper-cut art in post-modern fashion design [J]. Guo Li, Chen Lian. Foreign silk. 2008 (06) (in Chinese)

[7] Analysis of the carving patterns of Ming and Qing furniture. [J]. Yu Xiao Hong. Furniture. 2008 (05) (in Chinese)

[8] On the application of splicing design in clothing design [J]. Liu Hongluan, Li Yi. Textile Science and technology progress. 2008 (01) (in Chinese)

[9] Modern evolution of paper-cut [J]. Rao Su Guang. Grand View of art. 2007 (09) (in Chinese)

[10]Comparison of Northern Shaanxi paper-cut and Han Stone Relief -- Also on the inheritance of folk art to primitive culture [J]. Li Dongfeng. National art research. 2006 (06)(in Chinese) 